Check for updates

Cite this: RSC Adv., 2019, 9, 15727

Received 13th January 2019

Accepted 30th April 2019

DOI: $10.1039 / c 9 r a 00308 h$

rsc.li/rsc-advances

\section{Highly efficient methyldiethanolamine (MDEA) removal and light naphtha purification via synergistic effect of molecular sieves and fixed adsorption bed}

\begin{abstract}
Bin Zhang, Zhishan Bai, (D) * Bingjie Wang and Huiqing Luo
Light naphtha is an important raw material for the production of benzene, toluene, and xylene from cracking in tubular furnaces for the production of ethylene and propylene. Light naphtha contains MDEA which is left behind after desulfurization. MDEA remaining in light naphtha will cause high alkalinity of light naphtha, which decreases product quality and increases costs. Additionally, MDEA itself is not easy to degrade and is harmful to human skin, so the removal of MDEA is of great significance for the purification of light naphtha and the protection of the environment. In this paper, a molecular sieve (13X) is compared with silica gel and resin (NKA-9) as a means of removing MDEA from light naphtha via synergism with a fixed adsorption bed. The adsorption capacity decreased in the order of $13 \mathrm{X}>$ NKA-9 > silica gel, with values of $53.189,45.889$ and $34.863 \mathrm{mg} \mathrm{g}^{-1}$, respectively. Similarly, the effectiveness of steam for $13 \mathrm{X}$ regeneration after adsorption saturation was investigated, and the steam regeneration restored $95 \%$ of the activity of the fresh 13X. Furthermore, the adsorption mechanism of MDEA in light naphtha by $13 \mathrm{X}$ was studied, and it was confirmed that the adsorption process was dominated by chemisorption, supplemented by physisorption. The $-\mathrm{OH}$ and $-\mathrm{NH}_{2}$ functional groups were the main groups involved in the chemisorption, and capillary action and hydrogen bond action may be involved in physisorption.
\end{abstract}

\section{Introduction}

In the petrochemical industry, light naphtha is used as an important raw material for the production of benzene, toluene, and xylene from cracking in tubular furnaces for the production of ethylene and propylene. Nevertheless, the hydrogen sulfide generated in the process of light naphtha production will not only affect the quality of the naphtha but also do harm to the atmosphere and the human race. Thus, it is necessary to control the hydrogen sulfide content. At present, the light naphtha desulfurization processes are divided into dry desulfurization and wet desulfurization. ${ }^{1-3}$ MDEA desulfurization, a kind of wet desulfurization, is widely used because of its chemical stability and low regeneration loss. ${ }^{4}$ However, owing to the thorough mixing of light naphtha and the MDEA solution in the course of deamination, the light naphtha will inevitably entrain a proportion of MDEA droplets from the MDEA wash tank, which will increase the $\mathrm{pH}$ of light naphtha from around 7 to around 9.5. When this light naphtha is used to modulate gasoline, the MDEA will be brought in, resulting in a high nitrogen content, which pollutes the environment after

State Environmental Protection Key Laboratory of Environmental Risk Assessment and Control on Chemical Process, East China University of Science and Technology, Shanghai 200237, China. E-mail: baizs@ecust.edu.cn; Tel: +86-21-64253693 combustion. Additionally, when the light naphtha is processed again, the MDEA poisons the catalyst and increases the operating cost. ${ }^{5-7}$ Moreover, MDEA itself is not easy to degrade and is harmful to human skin, so the removal of MDEA is of great significance for the purification of light naphtha and the protection of the environment.

Gas chromatography is usually used to measure the concentration of organic chemicals. Nevertheless, as there is currently no standard for the detection of MDEA concentration and the method of gas chromatography is limited especially when the concentration of MDEA is less than $10 \mathrm{mg} \mathrm{L}^{-1}$, gas chromatography detection is difficult and inaccurate..$^{8,9}$ By contrast, measuring $\mathrm{pH}$ constitutes a simple and feasible method, because of the link between MDEA concentration and $\mathrm{pH}$. This paper measured the $\mathrm{pH}$ of light naphtha in order to measure the concentration of MDEA based on this characteristic, since MDEA is weakly alkaline.

In the literature, there is no research relevant to the removal of MDEA, so consider the commonly used two-phase separation methods as references. Generally, two-phase separation methods include gravity sedimentation, ${ }^{\mathbf{1 0}, 11}$ extraction, ${ }^{\mathbf{1 2 , 1 3}}$ centrifugal separation, ${ }^{\mathbf{1 4 , 1 5}}$ coalescence separation, ${ }^{\mathbf{1 6 , 1 7}}$ membrane separation, ${ }^{\mathbf{1 8 , 1 9}}$ and adsorption. ${ }^{20,21}$ Among these separation methods, adsorption has been widely used in the petrochemical industry owing to characteristics such as fast 
adsorption rate, large adsorption capacity, simple regeneration and reusability. ${ }^{22,23}$ Commonly, silica gel, resin and molecular sieves are used to remove adsorbates from water or the organic phase. It is acknowledged that the adsorption effect of the adsorbents is different for different adsorbed substances, so the work we should do is to select a suitable adsorbent according to the nature of the adsorbate. 13X, a type of molecular sieve, has been widely used in chemical separations such as the adsorption of inorganics and organics because of its advantages of high porosity, ${ }^{24-26}$ uniform pore size, ${ }^{27,28}$ simple regeneration, ${ }^{29,30}$ good regeneration performance, ${ }^{31-33}$ etc. In addition, adsorbents such as silica gel and resin have also been used in chemical adsorption, and have achieved great results. ${ }^{34-37}$

Although the adsorption method has been widely used in the chemical industry, the literature lacks reports on the exploration of the removal of MDEA from light naphtha by adsorbents. To fill in this research gap, the performance and mechanism of 13X adsorption of MDEA in light naphtha, at different adsorbent dosages, times and temperatures, were compared with those of silica gel and NKA-9. Moreover, the capacity of $13 \mathrm{X}$ to remove MDEA from light naphtha via the synergism with a fixed adsorption bed was studied, and the effects of temperature and flow rate on adsorption breakthrough curve were probed in order to solve the industrial problem. Furthermore, the surface structure of $13 \mathrm{X}$ was observed at high magnification through a scanning microscope (SEM) (S-3400N, Hitachi, Japan). Fourier-transform infrared (FT-IR) spectroscopy (Nicolet-6700, Thermo Fisher, USA) was carried out to provide information about the characteristic peaks of the groups. X-ray photoelectron spectroscopy (XPS) (ESCALAB 250Xi, Thermo Fisher, UK) was used to characterize the binding energy between the adsorbent elements to determine which reactive functional groups were involved in the adsorption process.

\section{Materials and methods}

\subsection{Material}

Working light naphtha was supplied by the Chinese Shanghai Petrochemical Co., Ltd, in which the concentration of MDEA was about $5 \mathrm{ppm}$. Adsorbent materials: NKA-9 was purchased from a laboratory reagent store in Tianjin City China, whereas 13X and silica gel were purchased from Chinese Gongyi Tenglong Water Treatment Co., Ltd.

\section{2. $\quad$ Fixed adsorption bed}

As a commonly used packed bed reactor, the fixed adsorption bed plays a vital part in the adsorption and desorption process. ${ }^{38}$ Fixed adsorption beds can be divided into two types, vertical and horizontal; vertical fixed adsorption beds include a cylindrical type and a multilayer type.$^{39}$ In this paper, a cylindrical vertical fixed adsorption bed was designed, and the adsorbents were placed in the fixed adsorption bed in a stacked form, as shown in Fig. 1. The fixed adsorption bed, with a Tpiece at each end to facilitate the adsorption and desorption processes, was entirely detachable and had an aspect ratio of approximately $9: 1$.

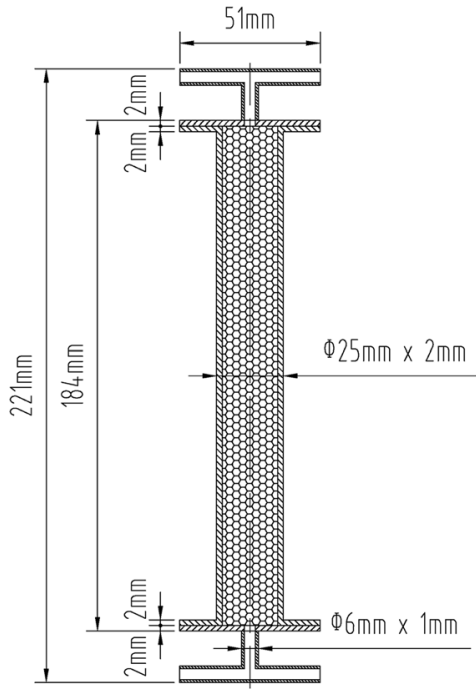

Fig. 1 Fixed adsorption bed schematic.

\subsection{Experiments}

2.3.1. Trade-off standard. As the determination of MDEA by gas chromatography is both challenging and timeconsuming, and when MDEA concentration is less than $10 \mathrm{mg} \mathrm{L}^{-1}$, it is difficult to analyze, since MDEA is alkaline, the value of the $\mathrm{pH}$ could reflect the concentration of MDEA, and so $\mathrm{pH}$ was used to determine the content of MDEA. In order to investigate the relationship between concentration and $\mathrm{pH}$, a series of aqueous MDEA solutions was prepared and the $\mathrm{pH}$ was measured.

2.3.2. Batch adsorption. All batch adsorption experiments were performed with $2.1 \mathrm{~g}$ to $2.5 \mathrm{~g}$ of the adsorbent silica gel, NKA-9 or $13 \mathrm{X}$ in $50 \mathrm{~mL}$ glass bottles with $30 \mathrm{~mL}$ of light naphtha with an initial $\mathrm{pH}$ of approximately 9.5. The flasks were shaken at $160 \mathrm{rpm}$ in a water bath equipped with a thermostat at a room temperature of $298 \mathrm{~K}$.

The effects of adsorbent dosage, adsorption time and temperature on the adsorption were compared for the three adsorbents. When comparing the effect of the dosage of adsorbent, the adsorption time was maintained at $2 \mathrm{~h}$ and the adsorption temperature was kept at $298 \mathrm{~K}$, while the amount of adsorbent varied from $2.1 \mathrm{~g}$ to $2.5 \mathrm{~g}$. Similarly, the effect of adsorption time of the above three adsorbents was determined at a temperature of $298 \mathrm{~K}$ and adsorbent dosage of $2.3 \mathrm{~g}$. In order to investigate the influence of temperature, experiments were conducted at 283 to $313 \mathrm{~K}$ for the same adsorption time of $0.5 \mathrm{~h}$, with an adsorbent dosage of $2.3 \mathrm{~g}$.

2.3.3. Dynamic adsorption. Through the above batch experiments, 13X was selected as the best adsorbent for the removal of MDEA from light naphtha, and dynamic adsorption experiments were carried out to further explore its adsorption performance in fixed bed so as to provide guidance for industrial applications. With a flow rate of $400 \mathrm{~mL} \mathrm{~h}^{-1}$, the effects of three different operating temperatures, $293 \mathrm{~K}, 303 \mathrm{~K}$ and $313 \mathrm{~K}$, on the adsorption by $13 \mathrm{X}$ were investigated. Samples were taken at 0.5 hour intervals until the adsorbents reached saturation. Additionally, at a temperature of $293 \mathrm{~K}$, the effect of adsorption 


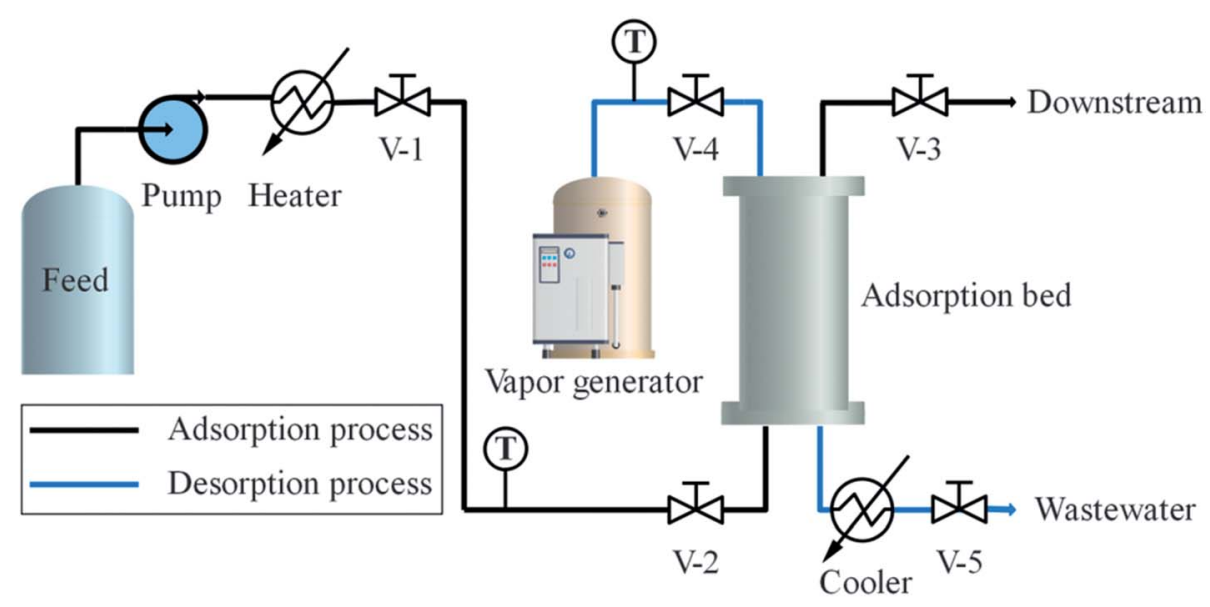

Fig. 2 Dynamic adsorption and desorption process.

by $13 \mathrm{X}$ at different flow rates, $400 \mathrm{~mL} \mathrm{~h}^{-1}, 500 \mathrm{~mL} \mathrm{~h}^{-1}$ and $600 \mathrm{~mL} \mathrm{~h}^{-1}$, was investigated.

The experimental apparatus designed to test the adsorption and desorption performance of MDEA is illustrated in Fig. 2. In the adsorption system, the light naphtha from the feeding bottle flowed into an electric heater pumped by a metering pump, and thereafter passed through a regular valve (V-1) and a check valve (V-2) into the adsorption bed. Subsequently, the purified light naphtha flowed through the regular valve (V-3) into the downstream.

2.3.4. Desorption experiment. In the desorption system, steam was applied as a regenerant to desorb MDEA from 13X. As shown in Fig. 2, steam at a rated temperature of $443 \mathrm{~K}$ passed through a regular valve $(\mathrm{V}-4)$, and then flowed from the top to the bottom of the adsorption bed. Steam-carried MDEA entered the water cooler and was cooled to approximately $303 \mathrm{~K}$ before it was discharged through a regular valve (V-5) into the environment. Whether the regeneration was accomplished was determined by measuring the $\mathrm{pH}$ of the steam condensate.

2.3.5. Supplemental experiment. In order to study the effects of different initial concentrations of MDEA and temperature on the adsorption and to exclude the interference of other substances in the light naphtha, $n$-hexane, with similar boiling point to light naphtha, was used as solvent, and a solution of $100-500 \mathrm{mg} \mathrm{L}^{-1}$ MDEA in $n$-hexane was prepared to study the adsorption of the adsorbent at 293-313 K. In the experiment, the amount of the adsorbent used was $0.1 \mathrm{~g}$, and the amount of the $n$-hexane solution was $30 \mathrm{~mL}$.

\section{Results and discussion}

\subsection{Physicochemical properties}

The physical properties of silica gel, NKA-9 and 13X are listed in Table 1. Among them, 13X had the largest specific surface area and the smallest average pore diameter, which could be an explanation for the subsequent high $13 \mathrm{X}$ adsorption capacity. Because of the large specific surface area, there were relatively more adsorption sites. In the case where the pore size was larger than the MDEA molecule, the smaller the pore size, the lower the probability of adsorption to other adsorbates.

Scanning electron microscope (SEM) photographs of 13X, NKA- 9 and silica gel are shown in Fig. 3 . It can be seen from Fig. 3 that the surface of the silica gel was smoother than the surfaces of NKA-9 and 13X. Compared with silica gel, NKA-9 had more surface wrinkles, that is, more adsorption sites, which was the reason why its effect was better than that of silica gel. In contrast to the two adsorbents, the 13X surface presented many microspheres arranged on the surface; the arrangement was relatively neat and the pores were relatively developed. The regular surface and the development of the channels made it easier to adsorb MDEA.

\subsection{Trade-off standard analysis}

Fig. 4 presents the relationship between MDEA concentration and $\mathrm{pH}$. As the concentration of MDEA increased from 0 to $50 \%$, the $\mathrm{pH}$ also rose from 7.18 to 11.20 . It could be concluded that as the concentration of MDEA increased, the $\mathrm{pH}$ also increased

Table 1 Physicochemical properties of the adsorbents silica gel, NKA-9 and 13X

Adsorbent type

Appearance

Specific surface area $\left(\mathrm{m}^{2} \mathrm{~g}^{-1}\right)$

Average aperture (nm)

Polarity

Chemical stability

$\mathrm{Al} / \mathrm{Si}$ ratio
Silica gel

Transparent spherical particles

350-400

11

Polar

Stable
NKA-9

Milky white opaque spherical particles 250-290

16

Polar

Stable
13X

Light yellow spherical particles 440-500

9

Polar

Stable

2.7 


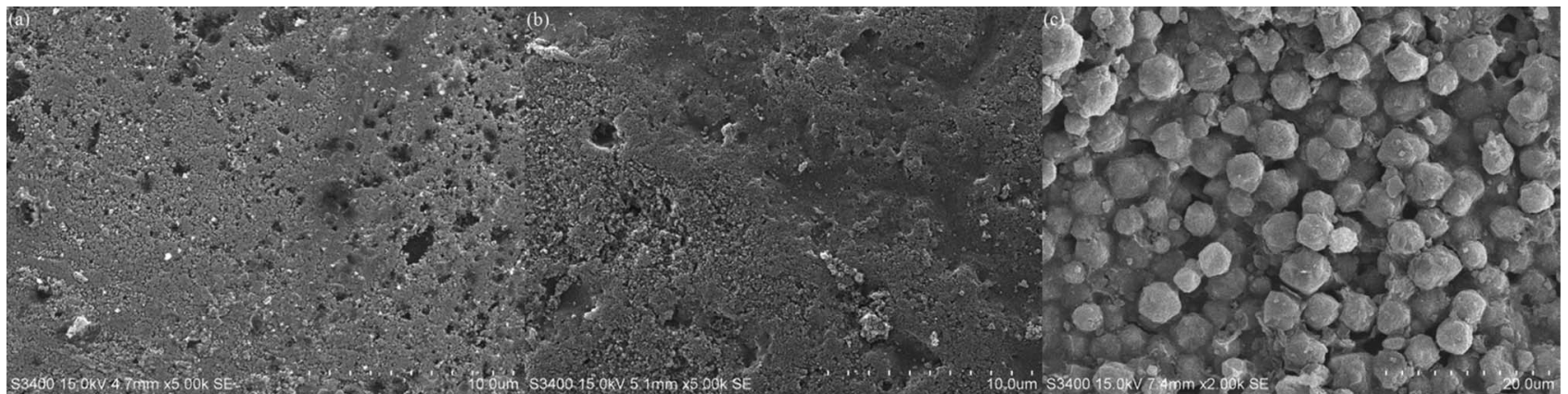

Fig. 3 Micromorphology of silica gel (a), NKA-9 (b) and 13X (c).

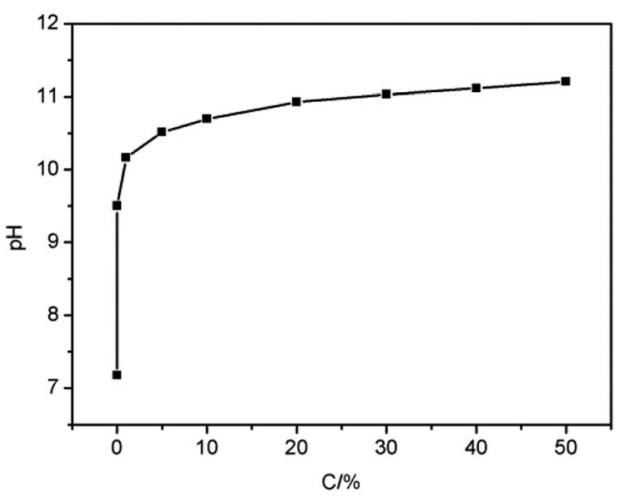

Fig. 4 Relationship between MDEA concentration and $\mathrm{pH}$.

continuously, indicating that MDEA concentration and $\mathrm{pH}$ were positively correlated, which proved that it was feasible to measure the MDEA concentration by $\mathrm{pH}$.

Moreover, in this research, the adsorption capacity was positively correlated to the $\Delta \mathrm{pH}$; hence the $\Delta \mathrm{pH}$ of naphtha could be measured to indirectly indicate the adsorption capacity. The test method was as follows. A certain amount of petroleum product was placed in a separating funnel, after which the same volume of water was added to the separating funnel. The separating funnel was gently shaken for a certain time until the two phases were well mixed, and then left for the layers to separate. After the two layers had separated, the $\mathrm{pH}$ of

(a)

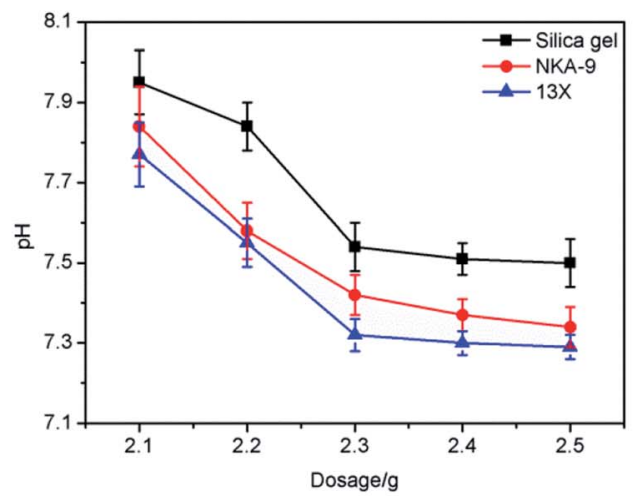

the aqueous solution was measured, which was regarded as the $\mathrm{pH}$ of the petroleum product.

\subsection{Batch adsorption}

3.3.1. Effect of adsorbent dosage. Fig. 5 presents the effect of dosage of silica gel, NKA-9, and 13X on adsorption. It can be seen from Fig. 5 that as the mass of the adsorbents increased, the $\mathrm{pH}$ gradually decreased, and the $\Delta \mathrm{pH}$ increased simultaneously, indicating that the MDEA in the light naphtha gradually decreased, that is, when the mass of the adsorbents increased, the adsorption effect became better.

This was because, as the mass of the adsorbents increased, the number of adsorption sites increased, and more MDEA could be adsorbed onto the adsorbents. The adsorption capacity of the three adsorbents decreased in the order: $13 \mathrm{X}>\mathrm{NKA}-9>$ silica gel.

In addition, it can be seen from Fig. 5 that when the adsorbents' mass reached $2.3 \mathrm{~g}$, the increased dosage of adsorbent exhibited less effect on $\mathrm{pH}$, which indicated that $2.3 \mathrm{~g}$ of adsorbent was sufficient to treat $30 \mathrm{~mL}$ of light naphtha with a pH of 9.5. Thus, the amount of adsorbent used in the subsequent experiments was $2.3 \mathrm{~g}$.

3.3.2. Effect of adsorption time. Fig. 6 represents the effect of adsorption time on the adsorption of the three adsorbents. It can be seen from Fig. 6 that as the adsorption time was extended, the $\mathrm{pH}$ decreased and the $\Delta \mathrm{pH}$ increased, that is, the adsorption effect became better. When the adsorption time was (b)

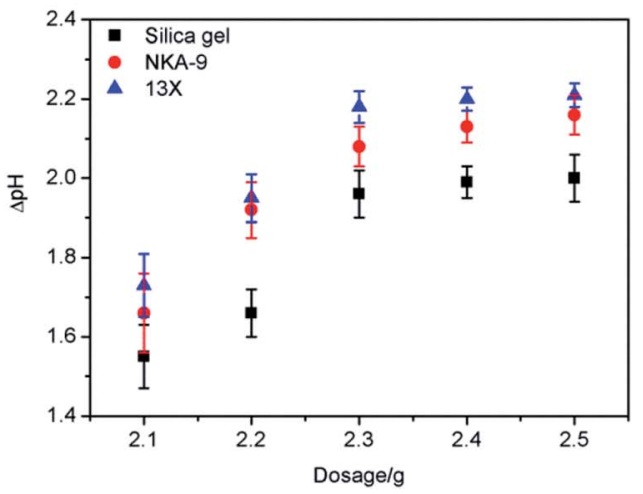

Fig. 5 Effect of adsorbent dosage on adsorption. 
(a)

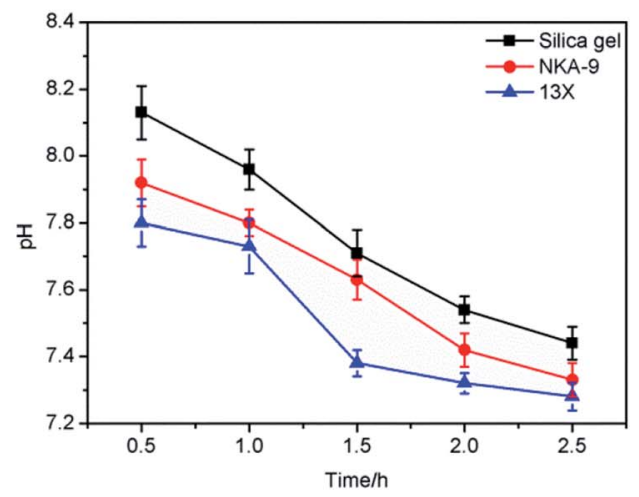

(b)

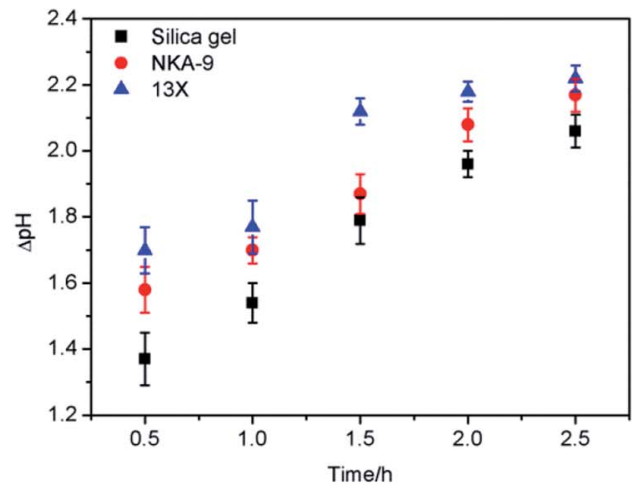

Fig. 6 Effect of adsorption time on adsorption.

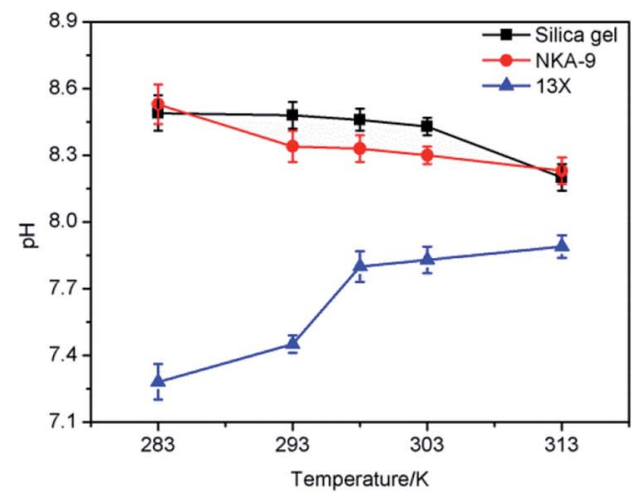

(b)

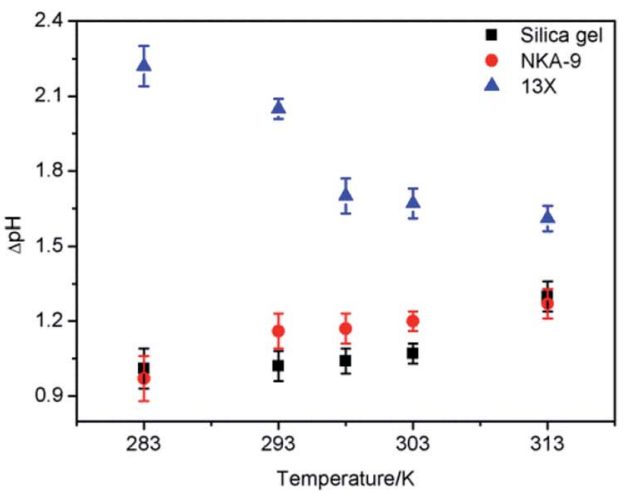

Fig. 7 Effect of temperature on adsorption.

prolonged, MDEA had more opportunities to combine with the adsorption sites. Initially, adsorption occurred at the surface of the adsorbents. Once adsorbed to a certain extent, the adsorbate would diffuse through the pores into the interior of the adsorbents; thus, further MDEA in the light naphtha was adsorbed. It is worth noting that with the increase of adsorption time, the adsorption effect of $13 \mathrm{X}$ was always better than that of silica gel and NKA-9.

3.3.3. Effect of temperature. The effect of temperature on the adsorption by the three adsorbents revealed different adsorption processes. As shown in Fig. 7, when the temperature rose, the adsorption effects of silica gel and NKA-9 became better; opposite to this, the adsorption effect of $13 \mathrm{X}$ became worse, indicating that the adsorption processes of silica gel and NKA-9 were probably endothermic processes, while the adsorption process of $13 \mathrm{X}$ was probably an exothermic process. In the studied temperature range, the adsorption effect of $13 \mathrm{X}$ was superior to that of the other two adsorbents under the same conditions.

\subsection{Dynamic adsorption}

From the results of the above batch adsorption experiments, it could be seen that the adsorption effect of $13 \mathrm{X}$ was superior to that of the other two adsorbents, and it was decided to further explore its dynamic adsorption performance and regeneration performance.

3.4.1. Effect of temperature on breakthrough curve. As may be distinguished from Fig. 8, the increase of the operating temperature from $293 \mathrm{~K}$ to $313 \mathrm{~K}$ contributed to the decrease of the breakthrough time from 6 to 2.5 hour. This behavior once again indicated that the adsorption was probably an exothermic process, and hence, as the operating temperature was increased, the equilibrium concentration on the solid phase

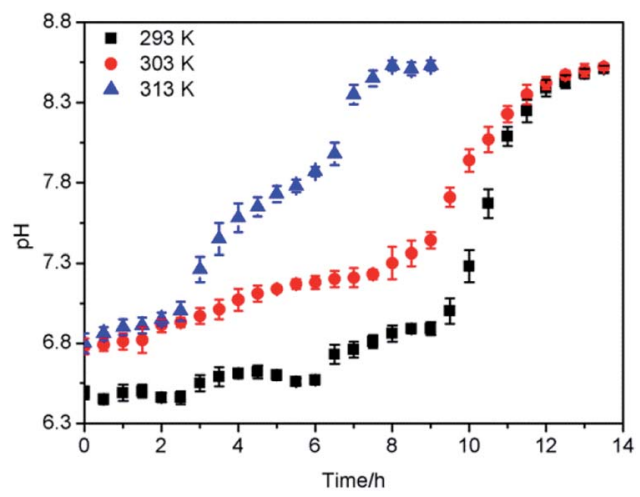

Fig. 8 Adsorption breakthrough curves at different temperatures. 


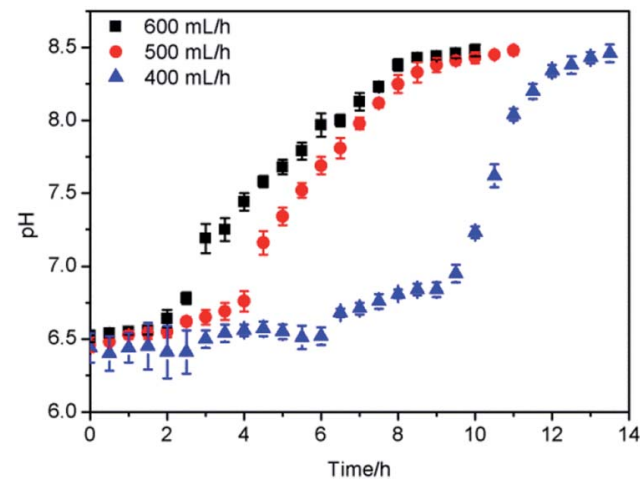

Fig. 9 Adsorption breakthrough curves at different flow rates.

decreased, which was also consistent with the results of batch experiments. This meant that the equilibrium was reached quickly for higher operating temperature.

3.4.2. Effect of flow rate on breakthrough curve. The effect of the flow rate on the outlet $\mathrm{pH}$ is shown in Fig. 9. It was illustrated that breakthrough generally occurred faster with higher flow rate. The time to reach saturation adsorption decreased significantly with the increase of the flow rate. At a high inlet flow rate, light naphtha had less time in contact with 13X, which resulted in lower removal of MDEA in the column. At a high flow rate, the solute diffused on the surface of the adsorbents due to insufficient residence time in the column, and the adsorption capacity was low, so the solute left the column before equilibrium occurred. ${ }^{40}$

\subsection{Study of mechanism}

3.5.1. XPS. X-ray photoelectron spectroscopy (XPS) was used to characterize the binding energy between the elements in 3X. Fig. 10 shows the XPS spectrum before and after $13 \mathrm{X}$ adsorption of MDEA. It can be seen from the figure that the elemental peaks of $13 \mathrm{X}$ after adsorption were significantly reduced, indicating that the active group containing these elements participated in the adsorption process.

Fig. 11(a) and (b) show the C1s energy spectrum of $13 \mathrm{X}$ before and after adsorption of MDEA. The $13 \mathrm{X}$ carbon component after adsorption increased from one peak at $285 \mathrm{eV}$ to two

(a)

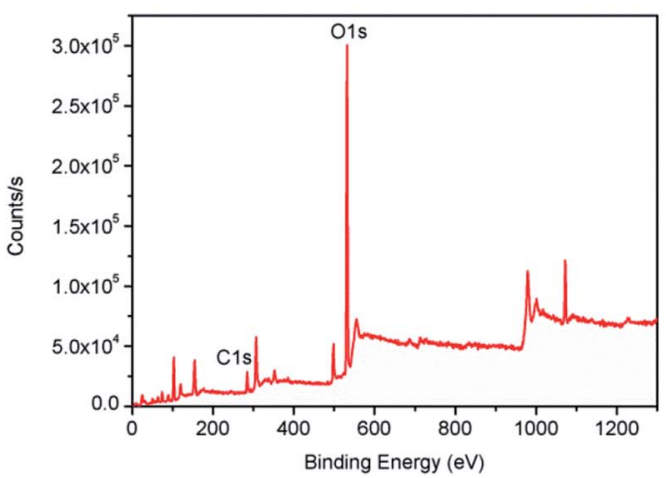

peaks at $285 \mathrm{eV}$ and $286.6 \mathrm{eV}$, of which the $285 \mathrm{eV}$ and $286.6 \mathrm{eV}$ peaks represented $\mathrm{C}-\mathrm{H}$ and $\mathrm{C}-\mathrm{OH}$ or $\mathrm{C}-\mathrm{N}$, respectively, indicating $\mathrm{C}-\mathrm{OH}$ or $\mathrm{C}-\mathrm{N}$ was probably involved in the reaction in the course of the adsorption of MDEA. ${ }^{41}$ Fig. 11(c) and (d) show the N1s energy spectrum before and after 13X adsorption of MDEA. The 13X nitrogen component after adsorption increased from two peaks at $402.5 \mathrm{eV}$ and $400.6 \mathrm{eV}$ to three peaks at $402.4 \mathrm{eV}$, $400.4 \mathrm{eV}$ and $399.7 \mathrm{eV}$, of which $402.4 \mathrm{eV}, 400.4 \mathrm{eV}$ and $399.7 \mathrm{eV}$ represented $\mathrm{NH}_{4}{ }^{+}, \mathrm{C}-\mathrm{N}-\mathrm{C}$ and $-\mathrm{NH}-$, respectively, indicating that the $-\mathrm{NH}$ - group was possibly involved in the adsorption process. $^{42}$ Fig. 11(e) and (f) show the O1s energy spectrum before and after 13X adsorption of MDEA. 13X had the same oxygen component before and after adsorption of MDEA. In the 13X O1s energy spectrum after adsorption, $532.7 \mathrm{eV}, 531.9 \mathrm{eV}$ and $531.05 \mathrm{eV}$ represented $\mathrm{C}-\mathrm{OH}, \mathrm{C}-\mathrm{O}-\mathrm{C}$ and O-metal elements, respectively. Although the positions of oxygen-containing functional groups before and after adsorption had not switched, the competitiveness of $\mathrm{C}-\mathrm{OH}$ and $\mathrm{C}-\mathrm{O}-\mathrm{C}$ were reduced, indicating that $\mathrm{C}-\mathrm{OH}$ and $\mathrm{C}-\mathrm{O}-\mathrm{C}$ groups were likely to be involved in the adsorption. ${ }^{43}$

3.5.2. FT-IR. Fourier-transform infrared (FT-IR) spectroscopy analysis was carried out to provide information about the characteristic peaks of the functional groups, as shown in Fig. 12. The infrared spectra of the adsorbed $13 \mathrm{X}$ and the fresh 13X were basically the same, and they had the same absorption peaks at $979,751,561$, and $456 \mathrm{~cm}^{-1}$. The absorption peaks of 13X near 3475 and $1643 \mathrm{~cm}^{-1}$ were the $-\mathrm{OH}$ or $-\mathrm{NH}_{2}$ stretching vibration peak and $-\mathrm{OH}$ bending vibration peak arising from absorption of $\mathrm{H}_{2} \mathrm{O}$ in the moist air or MDEA in light naphtha, respectively. It can be seen that the absorption peaks near $3475 \mathrm{~cm}^{-1}$ of $13 \mathrm{X}$ after adsorption were slightly strengthened and shifted. Simultaneously, the stretching vibration peaks of $\mathrm{C}-\mathrm{H}$ and $\mathrm{C}-\mathrm{N}$ appeared at 2960.3 and $1411.2 \mathrm{~cm}^{-1}$ after adsorption. It was inferred that $-\mathrm{OH}$ or $-\mathrm{NH}_{2}$ was involved in the adsorption process. Additionally, the spectrum of the regenerated $13 \mathrm{X}$ was almost the same as the spectrum of the fresh 13X. This also illustrated the effectiveness of regeneration, which could restore the adsorption performance of the $13 \mathrm{X}$.

3.5.3. Analysis of supplemental experiments. The isothermal adsorption curve describes the interaction between adsorbates at a certain temperature. The commonly used

(b)

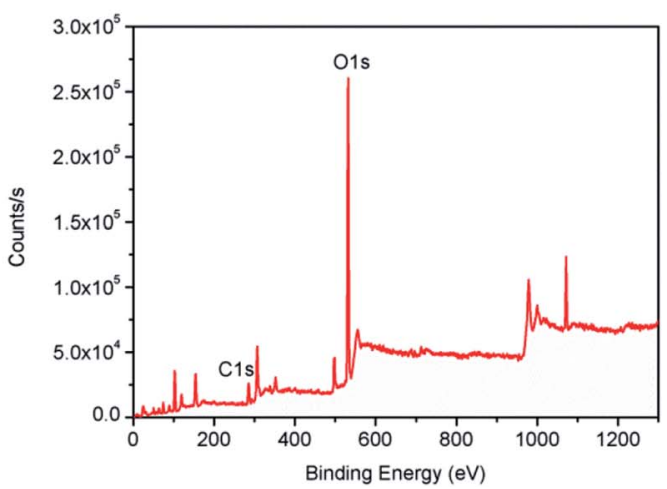

Fig. 10 XPS energy spectrum: (a) fresh 13X, (b) absorbed 13X. 
(a)

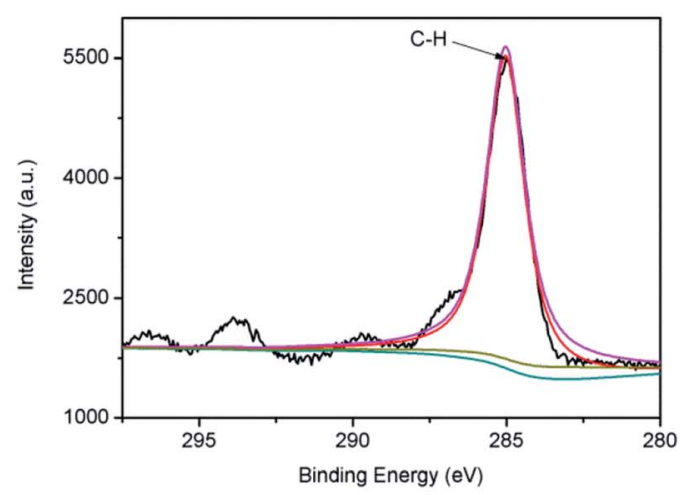

(c)

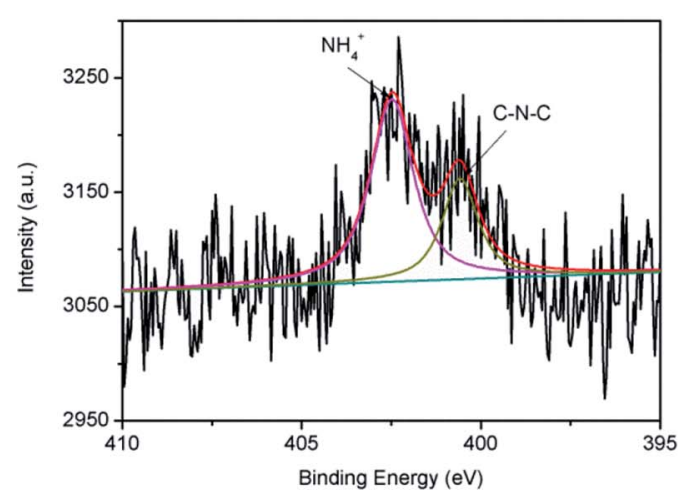

(e)

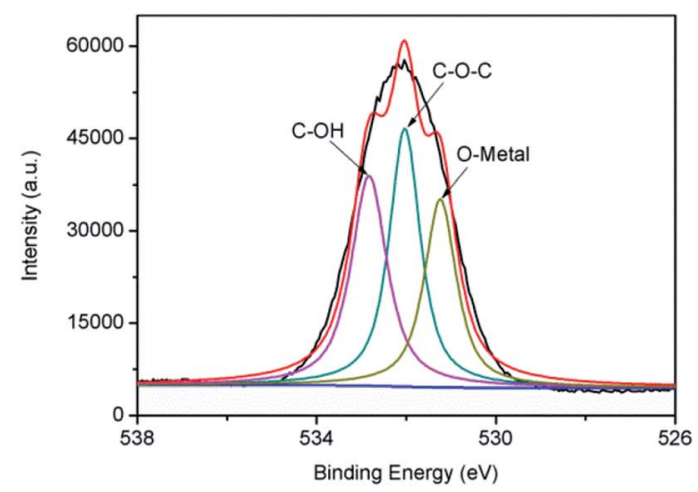

(b)

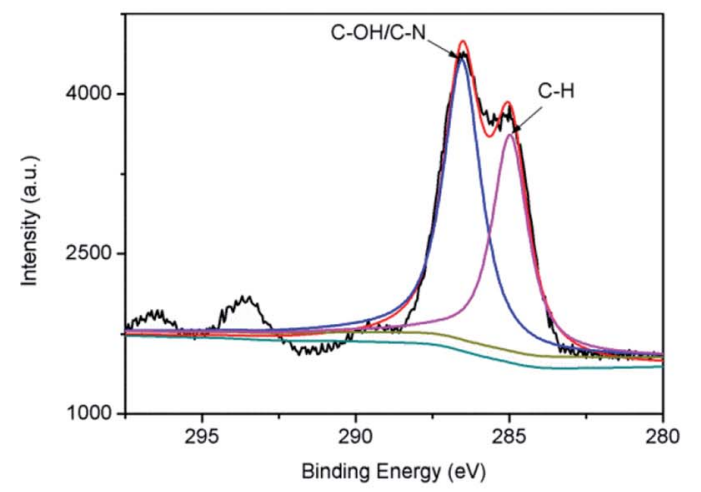

(d)

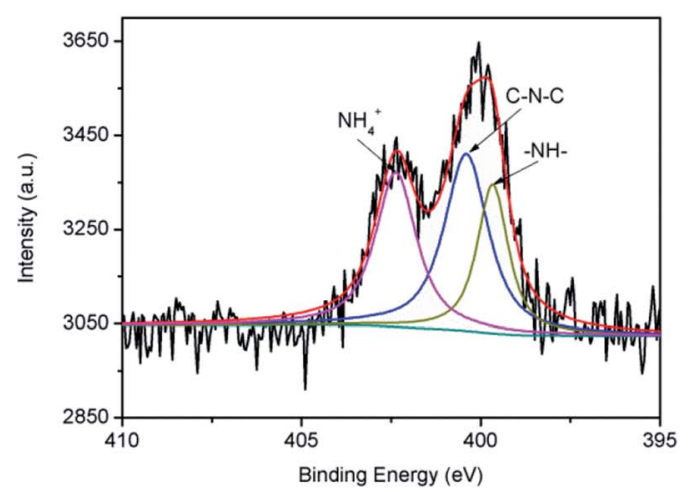

(f)

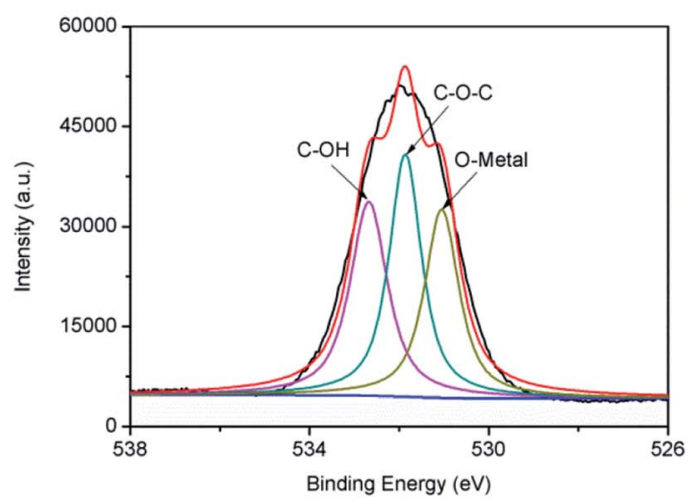

Fig. $11 \mathrm{C} 1 \mathrm{~s}(\mathrm{a}$ and b), N1s (c and d) and O1s (e and f) XPS energy spectra of fresh 13X (a, c and e) and absorbed 13X (b, d and f).

adsorption models are the Langmuir isotherm adsorption model and the Freundlich isotherm adsorption model. ${ }^{44}$ The adsorption equations for the Langmuir isotherm adsorption model and the Freundlich isotherm adsorption model are as follows:

$$
\begin{aligned}
& Q_{\mathrm{e}}=\frac{K_{\mathrm{L}} Q_{\mathrm{m}} C_{\mathrm{e}}}{1+K_{\mathrm{L}} C_{\mathrm{e}}} \\
& Q_{\mathrm{e}}=K_{\mathrm{F}} C_{\mathrm{e}}{ }^{1 / n}
\end{aligned}
$$

where $Q_{\mathrm{e}}$ is the equilibrium adsorption capacity $\left(\mathrm{mg} \mathrm{g}^{-1}\right), K_{\mathrm{L}}$ and $K_{\mathrm{F}}$ are the equilibrium constants of the Langmuir $\left(\mathrm{L} \mathrm{mg}^{-1}\right)$ and Freundlich $\left(\mathrm{mg} \mathrm{g}{ }^{-1}\left(\mathrm{~L} \mathrm{mg}^{-1}\right)^{1 / n}\right)$ systems, $Q_{\mathrm{m}}$ is the maximum adsorption capacity $\left(\mathrm{mg} \mathrm{g}^{-1}\right), C_{\mathrm{e}}$ is the equilibrium concentration $\left(\mathrm{mg} \mathrm{L}^{-1}\right)$, and $n$ is the equilibrium constant of the system.

Fig. 13 shows the isothermal adsorption curves of 13X, silica gel and NKA-9 after adsorption of MDEA, and the fitting parameters. That the isothermal adsorption of MDEA by the three adsorbents was more in line with Langmuir equation revealed that the adsorption process was dominated by chemisorption and the adsorption process was monolayer adsorption. The adsorption capacities of 13X, silica gel and NKA-9 for MDEA given by the Langmuir fitting curve were 53.189, 34.863 and $45.889 \mathrm{mg} \mathrm{g}^{-1}$, respectively, indicating that the adsorption 


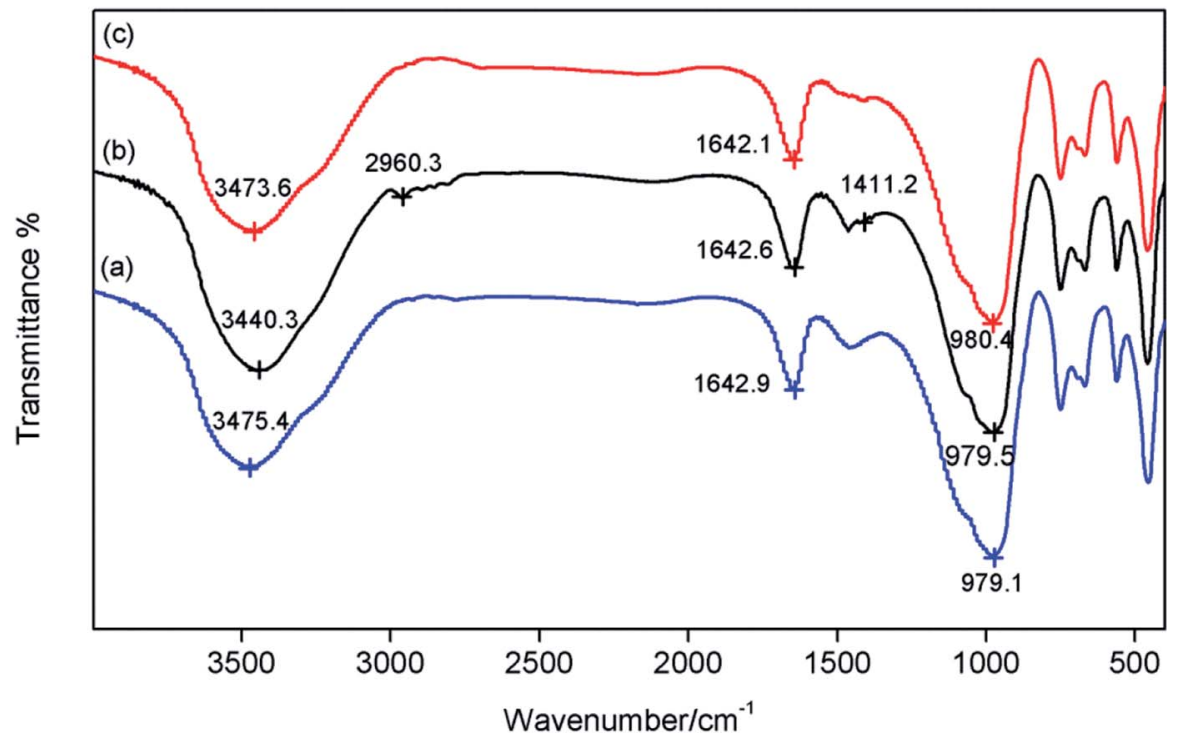

Fig. 12 FT-IR spectra of fresh 13X (a), absorbed 13X (b) and desorbed 13X (c).

of MDEA by $13 \mathrm{X}$ was better than that by the other two adsorbents, which was consistent with the results of the previous experiments.

The thermodynamic parameters enthalpy change $\left(\Delta H^{0}\right)$, entropy change $\left(\Delta S^{0}\right)$ and Gibbs energy change $\left(\Delta G^{0}\right)$ could be used to characterize the adsorption heat and the spontaneity of adsorption process. ${ }^{45}$ The parameters can be calculated using the following equations:

$$
K_{\mathrm{c}}=\frac{C_{\mathrm{Ae}}}{C_{\mathrm{Be}}}
$$

(b)
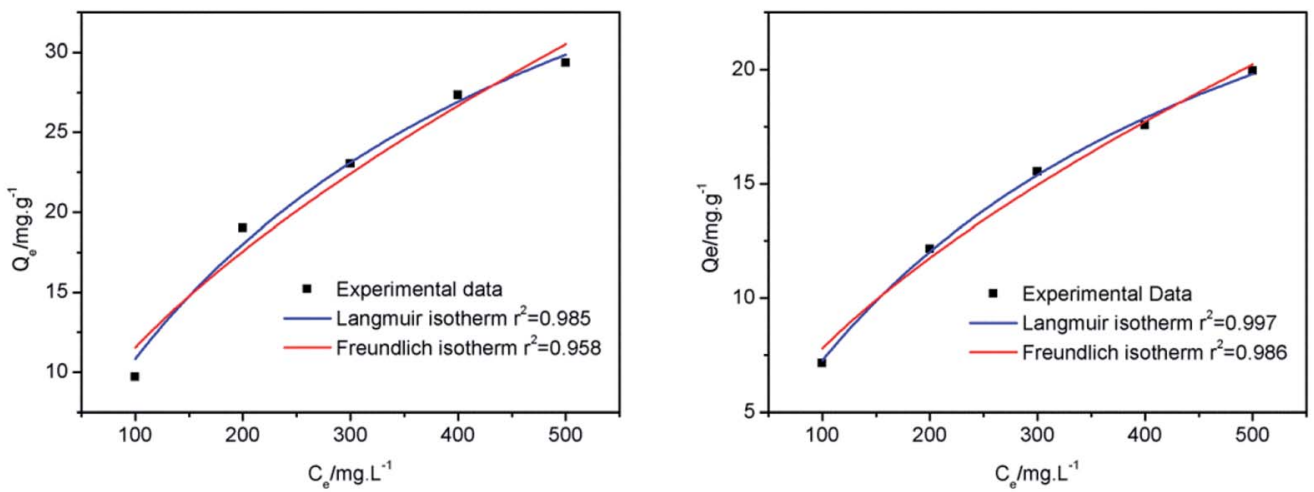

(c)

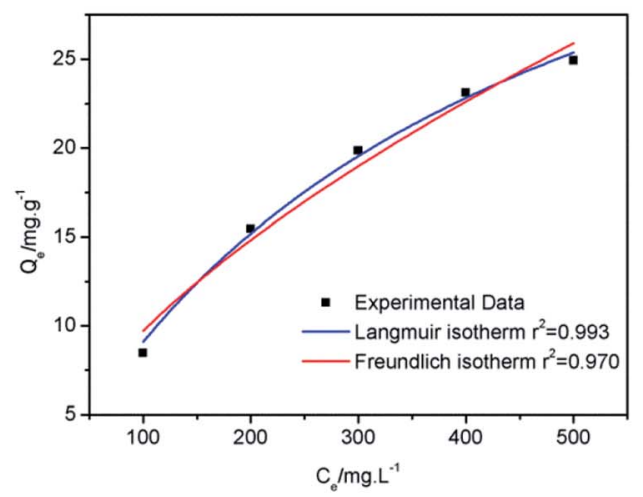

Fig. 13 Langmuir and Freundlich isothermal adsorption fitting curves of 13X (a), silica gel (b) and NKA-9 (c). 


$$
\ln K_{\mathrm{c}}=\frac{\Delta S^{0}}{R}-\frac{\Delta H^{0}}{R T}
$$

where $K_{\mathrm{c}}$ is the adsorption equilibrium constant, and $C_{\mathrm{Ae}}$ and $C_{\mathrm{Be}}$ are the contents $\left(\mathrm{mg} \mathrm{L}^{-1}\right)$, at equilibrium, of MDEA in the adsorbent and solution, respectively. $T$ is the adsorption temperature $(\mathrm{K})$ and $R$ is the gas constant, which is equal to $8.314 \mathrm{~J} \mathrm{~mol}^{-1} \mathrm{~K}^{-1}$.

The slope and intercept of the fitting line of $\ln K_{\mathrm{c}}$ and $1 / T$ could be used to calculate the values of $\Delta H^{0}$ and $\Delta S^{0}$, as shown in Fig. 14. The isothermal thermodynamic parameters calculated from Fig. 14 and eqn (4) are listed in Table 2. The $\Delta H^{0}$ of $13 \mathrm{X}$ was a negative value, indicating that the adsorption was an exothermic reaction. On the contrary, the $\Delta H^{0}$ of the silica gel and NKA-9 were positive values, indicating that the adsorption was an endothermic reaction. This also confirmed the hypothesis in the above experiment. The entropy change $\Delta S^{0}$ was positive, indicating that the randomness increased with the removal of MDEA by $13 \mathrm{X}$, silica gel and NKA-9. The negative value of $\Delta G^{0}$ indicated that the adsorption process occurred spontaneously. Additionally, as the temperature increased, the value of $\Delta G^{0}$ decreased, indicating that the degree of spontaneous adsorption of MDEA and the feasibility of adsorption increased.

3.5.4. Adsorption mechanism analysis. According to the isothermal adsorption fitting curve, the adsorption conformed to the Langmuir thermodynamic model, indicating that the adsorption was dominated by chemisorption. Combined with

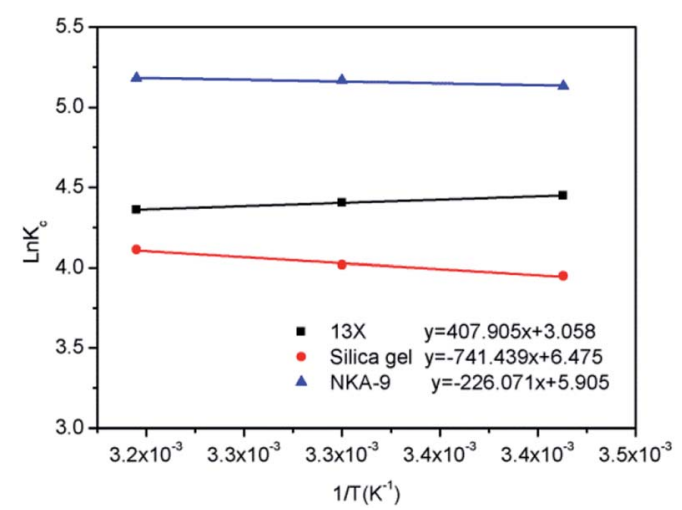

Fig. 14 Isothermal kinetic linear fitting of 13X, silica gel and NKA-9.

Table 2 Isothermal thermodynamic parameters of 13X, silica gel and NKA-9 at different temperatures

\begin{tabular}{|c|c|c|c|c|c|}
\hline Adsorbent & Temperature (K) & $\ln K_{\mathrm{c}}$ & $\begin{array}{l}\Delta G^{0} \\
\left(\mathrm{~kJ} \mathrm{~mol}{ }^{-1}\right)\end{array}$ & $\begin{array}{l}\Delta S^{0} \\
\left(\mathrm{~J} \mathrm{~mol}{ }^{-1} \mathrm{~K}^{-1}\right)\end{array}$ & $\begin{array}{l}\Delta H^{0} \\
\left(\mathrm{~kJ} \mathrm{~mol}^{-1}\right)\end{array}$ \\
\hline \multirow[t]{3}{*}{$13 \mathrm{X}$} & 293 & 4.449 & -10.838 & 25.424 & -3.391 \\
\hline & 303 & 4.406 & -11.099 & & \\
\hline & 313 & 4.360 & -11.346 & & \\
\hline \multirow[t]{3}{*}{ Silica gel } & 293 & 3.949 & -9.620 & 53.833 & 6.164 \\
\hline & 303 & 4.018 & -10.122 & & \\
\hline & 313 & 4.111 & -10.700 & & \\
\hline \multirow[t]{3}{*}{ NKA-9 } & 293 & 5.130 & -12.497 & 49.094 & 1.880 \\
\hline & 303 & 5.167 & -13.016 & & \\
\hline & 313 & 5.179 & -13.477 & & \\
\hline
\end{tabular}

the results of XPS and FT-IR analysis and the molecular formulae of $13 \mathrm{X}$ and MDEA, it could be concluded that the hydroxyl group and the amino group participated in the adsorption process. In addition, in accordance with the characteristics of the $13 \mathrm{X}$ porous structure, it can speculated that the adsorption process includes physisorption, such as capillary pore cohesion. ${ }^{\mathbf{4 6 , 4 7}}$ In addition to capillary pore cohesion, hydrogen bonding is also a type of physical adsorption force whose interaction is slightly stronger than the intermolecular force and weaker than the covalent bond and the ionic bond. ${ }^{\mathbf{4 8 , 4 9}}$

The adsorption of MDEA in light naphtha by $13 \mathrm{X}$ could be attributed to a combination of chemisorption and physisorption. The $-\mathrm{OH}$ and $-\mathrm{NH}_{2}$ functional groups were involved in chemisorption while physisorption was likely to be in the form of hydrogen bonds $\mathrm{O}-\mathrm{H} \cdots \mathrm{N}$ and $\mathrm{O}-\mathrm{H} \cdots \mathrm{O}$, which could also lead to the shift of characteristic peaks in FT-IR and XPS.

\subsection{Reusability}

Usually, the regeneration of the adsorbent is carried out by using $\mathrm{N}_{2}, \mathrm{C}_{2} \mathrm{H}_{4}$ or steam to remove the adsorbate on the surface of and inside the adsorbent. ${ }^{50,51}$

The saturated $13 \mathrm{X}$ was regenerated with steam, in two successive adsorption-regeneration operations, and the results obtained are shown in Fig. 15. It can be seen from Fig. 15 that when the saturated $13 \mathrm{X}$ was first regenerated, the regeneration effect was better. The saturation time after the first regeneration was $11.5 \mathrm{~h}$, which exceeded $95 \%$ of that of the fresh $13 \mathrm{X}$. After the $13 \mathrm{X}$ had been regenerated for the first time, it was subjected to a second round of adsorption-regeneration. When the saturated $13 \mathrm{X}$ after the second adsorption was regenerated once again, its adsorption activity was restored to $85 \%$ of that of the fresh adsorbent.

As shown in Fig. 16, by testing the $\mathrm{pH}$ of the steam condensate, it could be found that the $\mathrm{pH}$ first increased and subsequently decreased as the amount of MDEA from the surface of the adsorbents carried by the steam was relatively minor. After a certain time, the MDEA inside the adsorbents flowed out with the steam, so the $\mathrm{pH}$ rose, and with the removal of this part of the MDEA, the pH gradually decreased, until after about 3 hours it became almost neutral; at this point the regeneration was complete.

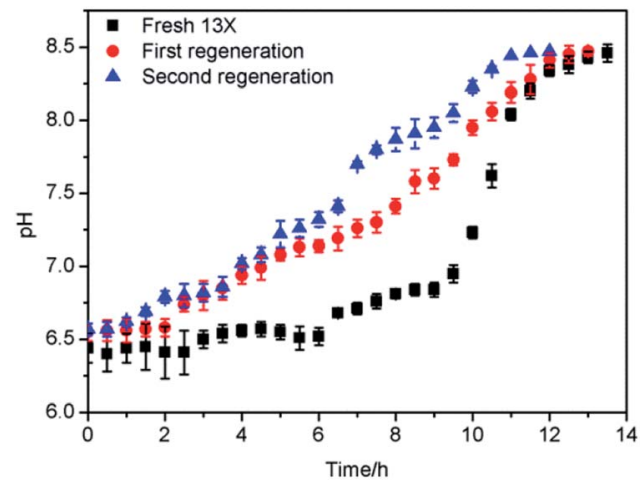

Fig. 15 Adsorption-regeneration effect curve. 


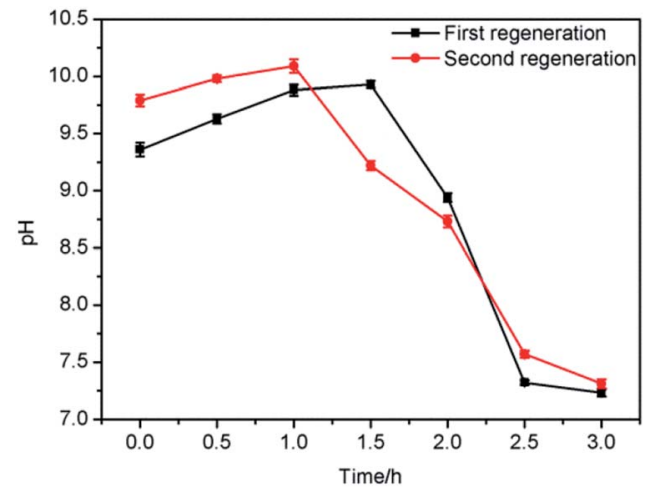

Fig. $16 \mathrm{pH}$ of steam condensate after regeneration.

\section{Conclusion}

The adsorption effects of silica gel, NKA-9 and 13X on MDEA in light naphtha were studied. The adsorption capacities from high to low were: $13 \mathrm{X}>$ NKA-9 > silica gel, with values of 53.189, 45.889 and $34.863 \mathrm{mg} \mathrm{g}^{-1}$, respectively. The results depicted that the isothermal adsorption of MDEA by the three adsorbents was more in line with the Langmuir equation, which showed that the adsorption process was dominated by chemisorption and the adsorption process was monolayer adsorption. In addition, the effects of temperature and flow rate on the $13 \mathrm{X}$ adsorption of MDEA in light naphtha were explored based on the use of a fixed adsorption bed, and it was found that as the flow rate and the temperature decreased, the adsorption effect became better. Similarly, the effectiveness of steam for $13 \mathrm{X}$ regeneration after adsorption saturation was investigated, and the steam regeneration effect was confirmed to be remarkable. Specifically, the first regeneration recovered in excess of $95 \%$ of the activity of the fresh $13 \mathrm{X}$, and after the second adsorptionregeneration process the adsorption activity of $13 \mathrm{X}$ was restored to $90 \%$ of that of the first regenerated $13 \mathrm{X}$ and $85 \%$ of that of the fresh 13X. In addition, the mechanism by which MDEA in light naphtha is adsorbed by $13 \mathrm{X}$ was studied, and it was found that the adsorption of MDEA in light naphtha by $13 \mathrm{X}$ was mainly chemisorption involving $-\mathrm{OH}$ and $-\mathrm{NH}_{2}$ functional groups.

\section{Conflicts of interest}

There are no conflicts to declare.

\section{Acknowledgements}

The authors are grateful for support from the National Natural Science Foundation of China, China (51578239) and the Scientific Research Projects of Shanghai, China (17DZ1202802).

\section{References}

1 H. Mehrara, B. Roozbehani, M. R. Shishehsaz, M. Mirdrikvand and S. I. Moqadam, Clean Technol. Environ., 2014, 16, 59-67.
2 G. Rui-tang, P. Wei-guo, Z. Xiao-bo, X. Hong-jian and R. Jianxing, Fuel, 2011, 90, 7-10.

3 G. Xiang, D. Honglei, D. Zhen, W. Zuliang, F. Mengxiang, L. Zhongyang and C. Kefa, Appl. Energy, 2010, 87, 2647-2651.

4 I. Zulkifli, H. Jingyi, S. Jayarathna and D. A. Eimer, Energy Procedia, 2017, 114, 1828-1833.

5 N. Revellin, H. Dulot, C. Lopez-Garcia, F. Baco and J. Jose, Energy Fuels, 2005, 19, 2438-2444.

6 B. Mandald and S. S. Bandyopadhyay, Environ. Sci. Technol., 2006, 40, 6076-6084.

7 L. Na, M. Xiaoliang, Z. Qingfang and S. Chunshan, Energy Fuels, 2010, 24, 5539-5547.

8 C. Hoe-Chee, L. Hoi-Sim and S. Mui-Tiang, J. Chromatogr. A., 2006, 1102, 214-223.

9 M. K. Woźniak, M. Wiergowski, J. Aszyk, P. Kubica, J. Namieśnik and M. Biziuk, J. Pharm. Biomed. Anal., 2018, 148, 58-64.

10 N. Fang-Hao, H. Zhi-De, Y. Hua, Z. Han-Song and Y. JianJian, Smart Mater. Struct., 2018, 27, 1-12.

11 L. Yanfeng, L. Ningbo, Q. Xiangqian, Z. Wenjun and Z. Rongtao, Physicochem. Probl. Miner. Process., 2018, 54, 837-846.

12 L. Bulgariu and D. Bulgariu, Sep. Purif. Technol., 2013, 118, 209-216.

13 S. Xiaoqi, P. Bo, J. Yang, C. Ji and L. Deqian, Sep. Purif. Technol., 2008, 63, 61-68.

14 L. N. Moskvin, Sep. Purif. Rev., 2016, 45, 1-27.

15 V. Pauer, E. Csefalvay and P. Mizsey, Open Chem., 2012, 11, 46-56.

16 M. Shaohua, K. Yong and C. Shibo, J. Dispersion Sci. Technol., 2014, 35, 103-110.

17 S. Agarwal, A. V. von, T. Stegmaier, H. Planck and A. Abhimanyu, Sep. Purif. Technol., 2013, 107, 19-25.

18 Z. Cheng, H. Shuai, W. Dingfei, X. Fang, Z. Fengxiu and Z. Guangxian, J. Mater. Sci., 2018, 53, 14398-14411.

19 P. Hrabánek, A. Zikánová, B. Bernauer, V. Fíla and M. Kočiř́k, Desalination, 2009, 245, 437-443.

20 Z. Yong, B. Zhishan, W. Bingjie, Z. Linlin and L. Wenqiang, Front. Chem. Sci. Eng., 2017, 11, 238-251.

21 B. Buczek and W. Chwiałkowski, Pol. J. Chem. Technol., 2008, 10, 19-21.

22 R. Waninge, P. Walstra, J. Bastiaans, H. Nieuwenhuijse, T. Nylander, M. Paulsson and B. Bergenståhl, J. Agric. Food Chem., 2005, 53, 716-724.

23 L. Li, Z. Jing, Y. Shaojun, H. Liqiang, T. Shengwei, L. Bin and S. O. Pehkonen, RSC Adv., 2016, 6, 78136-78150.

24 S. Svilović, D. Rušić and A. Bašić, Desalination, 2010, 259, 7175.

25 H. Tianbiao, L. Qiuying and J. Yonglin, J. Chem. Eng. Jpn., 2013, 46, 811-820.

26 Z. Hong, H. Lijie, M. Hongwen, Z. Yan, Z. Hongmei, L. Donghong and L. Shuping, J. Hazard Mater., 2008, 158, 577-584.

27 H. Fene, S. Chengke and H. Nengbang, Energy Procedia, 2011, 11, 2833-2839.

28 A. Paolo, C. Domenico, G. Nicola, I. Fabio and P. Francesco, J. Chem. Eng. Data, 2010, 55, 3655-3661. 
29 S. D. Manjare and A. K. Ghoshal, Sep. Purif. Technol., 2006, 51, 118-125.

30 G. Narin, V. F. D. Martins, M. Campo, A. M. Ribeiro, A. Ferreira, J. C. Santos, K. Schumann and A. E. Rodrigues, Sep. Purif. Technol., 2014, 133, 452-475.

31 C. A. Grande, J. Gascon, F. Kapteijn and A. E. Rodrigues, Chem. Eng. J., 2010, 160, 207-214.

32 K. M. Valkaj, A. Katović and S. Zrnčević, Ind. Eng. Chem. Res., 2011, 50, 4390-4397.

33 Y. Yunfeng, Z. Liangwei and W. Jiade, J. Air Waste Manag. Assoc., 2012, 62, 1227-1232.

34 S. Hong, L. Hangxi, A. Ping, H. Lin, L. Xingang and C. Shan, J. Taiwan Inst. Chem. Eng., 2017, 74, 218-224.

35 P. J. Vodianitskaia, J. J. Soares, H. Melo and J. M. Gurgel, Energy Convers. Manage., 2017, 132, 172-179.

36 Y. Jie, L. Cheng, D. Yue, L. Qun, L. Rui, Z. Jiuliang and D. Jianling, Food Chem., 2018, 268, 424-430.

37 M. B. Fathi, B. Rezai, E. K. Alamdari and R. D. Alorro, Russ. J. Appl. Chem., 2017, 90, 1504-1513.

38 F. E. Soetaredjo, A. Kurniawan, L. K. Ong, D. R. Widagdyo and S. Ismadji, RSC Adv., 2014, 4, 52856-52870.

39 A. B. Albadarin, C. Mangwandi, A. H. Al-Muhtaseb, G. M. Walker, S. J. Allen and M. N. M. Ahmad, Chin. J. Chem. Eng., 2012, 20, 469-477.

40 L. Xiaoqing, H. Qianlin, Q. Gaoxiang, S. Silan, X. Lian, H. Chao, C. Xuefang, L. Hailong and C. Xinde, Sep. Purif. Technol., 2016, 174, 222-231.
41 S. Shengling, W. Li and W. Aiqin, J. Hazard. Mater., 2006, 136, 930-937.

42 F. Jianwei, X. Qianqian, W. Xuechen, C. Zhonghui, Y. Ya, L. Shujun, W. Minghuan and X. Qun, J. Colloid Interface Sci., 2016, 461, 292-304.

43 G. Huai-min and C. Xian-su, Polym. Adv. Technol., 2004, 15, 89-92.

44 W. Bingjie, B. Zhishan, J. Haoran, P. Pepijn, L. Rafael, Z. Shuangliang and X. Jin, J. Hazard. Mater., 2019, 364, 192-205.

45 Z. Hong, H. Lijie, M. Hongwen, Z. Yan, Z. Hongmei, L. Do nghong and L. Shuping, J. Hazard. Mater., 2008, 158, 577584.

46 G. Siliang, W. Yujun, W. Tao, L. Guangsheng and D. Youyuan, Bioresour. Technol., 2009, 100, 996-999.

47 J. A. Hriljac, C. Tzu-Yu, F. E. Soetaredjo, S. P. Santoso, A. Kurniawan and S. Ismadji, $R S C A d v$., 2015, 5, 8368983699.

48 Y. A. Galkina, N. A. Kryuchkova, M. A. Vershinin and B. A. Kolesov, J. Struct. Chem., 2017, 58, 911-918.

49 R. Pažout, J. Maixner, J. Pecháček, B. Vilhanová and P. Kačer, Z. Kristallogr. Cryst. Mater, 2016, 231, 531-539.

50 Z. Yongxian, C. Wei, W. Pengfei and Z. Yimin, RSC Adv., 2018, 8, 13728-13738.

51 W. Tanthapanichakoon, P. Ariyadejwanich, P. Japthong, K. Nakagawa, S. Mukai and H. Tamon, Water Res., 2005, 39, 1347-1353. 